
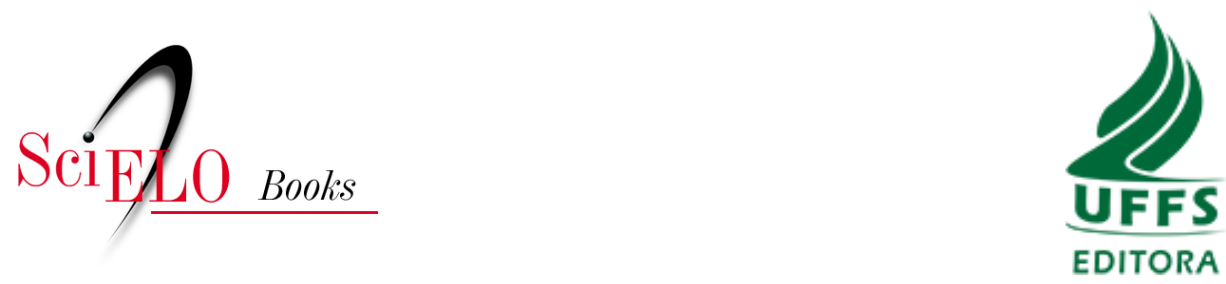

\title{
Desigualdades sociais e elitismo da educação superior brasileira
}

\author{
Rosileia Lucia Nierotka \\ Joviles Vitório Trevisol
}

\section{SciELO Books / SciELO Livros / SciELO Libros}

NIEROTKA, R.L., and TREVISOL, J.V. Desigualdades sociais e elitismo da educação superior brasileira. In: Ações afirmativas na educação superior: a experiência da Universidade Federal da Fronteira Sul [online]. Chapecó: Editora UFFS, 2019, pp. 13-39. ISBN: 978-655019-009-5. https://doi.org/10.7476/9786550190071.0002.

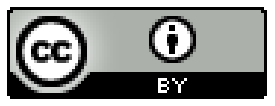

All the contents of this work, except where otherwise noted, is licensed under a Creative Commons Attribution 4.0 International license.

Todo o conteúdo deste trabalho, exceto quando houver ressalva, é publicado sob a licença Creative Commons Atribição 4.0. 


\section{DESIGUALDADES SOCIAIS E ELITISMO DA EDUCAÇÃO SUPERIOR BRASILEIRA}

"A história nos fez, pelo esforço de nossos antepassados, detentores de um território prodigiosamente rico e de uma massa humana metida no atraso, mas sedenta de modernidade e de progresso, que não podemos entregar ao espontaneísmo do mercado mundial. A tarefa das novas gerações de brasileiros é tomar este país em suas mãos para fazer dele o que há de ser, uma das nações mais progressistas, justas e prósperas da Terra."

Darcy Ribeiro

Neste capítulo destacam-se as raízes históricas e sociais das desigualdades que marcaram a formação do Brasil desde o seu processo de colonização. Aborda-se como essas desigualdades se manifestam na sociedade brasileira, mais especificamente na política educacional, tendo como foco o elitismo na educação superior, que constitui um dos problemas mais graves. Destacam-se, também, as estratégias utilizadas pelo Estado e pelas elites para que o acesso à educação superior, como um bem público, fosse sempre um privilégio de poucos. E, ainda, as perspectivas de democratização, a partir da Constituição Federal brasileira, de 1988. 


\section{RAÍZES HISTÓRICAS E SOCIAIS DAS DESIGUALDADES}

A educação superior brasileira, apesar de um longo processo de expansão, continua sendo marcadamente elitista e privatizada. Para compreender esse processo de elitização é preciso partir da desigualdade social como uma dimensão estruturante da formação do Brasil, desde o seu "descobrimento", em 1500. Diferentemente do que muitos fazem crer, o Brasil não é país pobre; é uma nação rica que convive com a pobreza e alimenta os mecanismos (re) produtores da desigualdade e da injustiça social. O ensino superior, em particular, é um bem simbólico desigualmente distribuído que legitima os saberes e as práticas, a partir dos quais os detentores dos títulos acadêmicos sentem-se em condições de exercerem determinados ofícios e relações de poder na sociedade.

Salienta-se a importância de estudar as raízes histórico-sociais das desigualdades sociais estruturantes do país, uma vez que a sociedade de hoje está diretamente vinculada às heranças escravocratas e coloniais. Para o desenvolvimento deste capítulo, recorre-se a importantes autores que, de uma perspectiva crítica, contribuíram com uma vasta produção teórica sobre a formação do Brasil: Sérgio Buarque de Holanda (1995), Darcy Ribeiro (2006), Florestan Fernandes (2006), Octavio Ianni (2004), Raimundo Faoro (1979), Caio Prado Júnior (1986), Gilberto Freyre (2006) e Celso Furtado (2007).

O sistema colonial brasileiro é marcado por iniciativas econômicas da exploração de produtos para atender os interesses da metrópole. No entanto, foram os portugueses que iniciaram essa envergadura colonizadora, tendo o pau-brasil e o açúcar como os primeiros produtos a serem explorados nas terras brasileiras. Conforme destaca Ribeiro (2006), alguns aspectos contribuíram para esse processo: as habilidades dos portugueses na condução de um sistema de fazendas no Brasil para a produção do 
açúcar e a experiência com o trabalho escravo. Mediado por um contexto de dominação estrangeira, o Brasil, ainda segundo o autor,

[...] foi regido primeiro como uma feitoria escravista, exoticamente tropical, habitada por índios nativos e negros importados. Depois, como um consulado, em que o povo sublusitano, mestiçado de sangues afros e índios, vivia o destino de um proletariado externo dentro de uma possessão estrangeira. (RIBEIRO, 2006, p. 404).

É, portanto, na sociedade colonial que se pode buscar as raízes que marcaram o surgimento das desigualdades sociais no Brasil presentes até os dias atuais, mediante novas configurações. Porém, a essência da estrutura de um país desigual, comandado por uma elite dominante, permaneceu.

Como colônia, o Brasil foi sendo inserido no capitalismo comercial e industrial para fornecer alimentos, minérios e madeira ao mercado europeu. A escravidão, ao longo de quase quatro séculos, respondeu pela oferta de mão de obra barata para a sociedade agrária, exportadora e dependente (PRADO JÚNIOR, 1986).

Faoro (1979, p. 203), de uma forma crítica e contextualizada, apresenta as características da sociedade colonial e a formação do patronato político brasileiro:

Esta minoria comanda, disciplina e controla a economia e os núcleos humanos. Ela vive, mantém-se e se articula sobre uma estrutura de classes, que, ao mesmo tempo que influencia o estamento, dele recebe o influxo configurador, no campo político. O patrimonialismo, de onde brota a ordem estamental e burocrática, haure a seiva de uma especial contextura econômica, definida na expansão marítima e comercial de Portugal.

O autor descreve que a estrutura de classes que se formou, aliada a uma elite agrária e vinculada aos propósitos do rei, sob uma tutela que vinha "de cima", deixava, secularmente, as classes sociais incapazes de se emancipar. O estamento se assentava e se desenvolvia sobre a classe 
proprietária e estava voltado totalmente para o capitalismo comercial. Sobre essa estrutura, o autor enfatiza que "a tradicional visão da sociedade da colônia dos dois primeiros séculos reduz as classes a duas, senão a uma, em seus dois polos extremos: o proprietário rural, com os engenhos e fazendas, contraposto à massa dos trabalhadores do campo, escravos e semilivres" (FAORO, 1979, p. 204).

Fernandes (2006, p. 51) traduz de forma bastante objetiva o conservadorismo reinante da ordem social estabelecida no período colonial:

A grande lavoura e a mineração, nas condições em que podiam ser exploradas produtivamente, impunham a perpetuação das estruturas do mundo colonial - da escravidão à extrema concentração de renda e ao monopólio do poder por reduzidas elites, com a marginalização permanente da enorme massa de homens livres que não conseguia classificar-se na sociedade civil e a erosão invisível da soberania nacional nas relações econômicas, diplomáticas ou políticas com as grandes potências.

O Brasil, a despeito de sua independência em 1822, manteve sua estrutura desigual, pois "as elites dirigentes dos estamentos senhoriais absorveram as funções que antes eram desempenhadas mediante a 'tutela colonial', privilegiando politicamente seu prestígio social" (FERNANDES, 2006, p. 60).

A monarquia constitucional, implantada no início do século XIX, não alterou em nada a ordem social. As elites mantiveram-se dispostas a manter o seu status quo ante e a defender a escravidão e a posse concentrada da terra. De acordo com Fernandes (2006), a monarquia constitucional empenhava-se mais pela apropriação dos meios de organização do poder criadas em detrimento das questões concernentes aos requisitos ideais de integração da sociedade nacional. O autor afirma:

Desde que não se pusessem em questão "os interesses sagrados da nação", abertamente confundidos e identificados pelos estamentos senhoriais com os interesses da lavoura e mola mestra do seu 
radicalismo político, havia uma vasta área para a assimilação de novas adaptações econômicas, políticas e sociais. E ela foi, de fato, palmilhada nas direções possíveis pelas elites que ocupavam o cenário histórico antes ou depois da consolidação do Estado nacional independente (FERNANDES, 2006, p. 73).

Fernandes (2006) destaca, também, que o sistema colonial era subserviente à economia mundial. No contexto do capitalismo comercial e industrial da época, Portugal não era um país de muitas condições econômicas, pois seus processos econômicos se davam por alguns grupos financeiros e por outros países que controlavam o poderio econômico dos produtos coloniais. Houve um período de grande estagnação da economia na colônia. E, à medida que vão se expandindo as possibilidades de desagregação do sistema colonial, a economia começa a ter bases mais firmes para a urbanização e, mais tarde, a industrialização no Brasil.

Houve, então, como menciona o autor (2006), o início de um período de urbanização, principalmente após a Independência do Brasil. Nesse contexto urbano começam a surgir as elites formadas por banqueiros, artesãos, funcionários públicos, dotados de um “espírito burguês”. Em ambos os momentos - rural e urbano -, mesmo após a Independência, manteve-se uma sociedade esclerosada por componentes oriundos do mundo colonial, caracterizado pela escravidão e pela dominação patrimonialista.

A Independência do Brasil, conforme enfatiza Fernandes (2006), significou uma primeira revolução social no Brasil, pois marca o fim da "era colonial" e torna-se uma referência para uma "época da sociedade nacional”. Trata-se de uma fase de transição para um novo tipo de autonomia política. Nas palavras do autor, “o poder deixará de se manifestar de fora para dentro, para organizar-se a partir de dentro, malgrada as injunções e as contingências que iriam cercar a longa fase do predomínio inglês na vida econômica, política e diplomática da nação" (2006, p. 50).

A despeito de sua áurea revolucionária, a Independência manteve seu conservadorismo social e político. Segundo Fernandes (2006), o lado 
revolucionário se destaca por despojar uma ordem social que foi herdada na sociedade colonial. E o seu lado conservador, pela preservação e fortalecimento de uma ordem social com poucas condições para engendrar uma autonomia necessária para a construção de uma nação. Dessa forma, as contradições que acompanhavam o desenvolvimento do país eram adversas, pois o sistema competitivo que estava se formando se chocava com um sistema estamental, com a persistência da escravidão. Os traços marcantes da sociedade escravocrata mantiveram-se fortes ao longo das décadas. Não sem razão, Freyre (2006, p. 44-45) destaca que a casa-grande é a atmosfera social de onde nasceu o Brasil:

A história social da casa-grande é a história íntima de quase todo brasileiro: da sua vida doméstica, conjugal, sob o patriarcalismo escravocrata e polígamo; da sua vida de menino; do seu cristianismo reduzido à religião de família e influenciado pelas crendices da senzala. [...] nas casas grandes foi até hoje onde melhor se exprimiu o caráter brasileiro: a nossa continuidade social.

Ribeiro (2006) também destaca a força das relações senhoriais na formação do Brasil. Segundo ele, “[...] todas as nossas instituições políticas constituem superfetações de um poder efetivo que se mantém intocado: o poderio do patronato fazendeiro" (p. 201). A distância social manteve-se estável entre ricos e pobres, brancos e negros, homens e mulheres.

A mentalidade de desprezo que a sociedade brasileira manteve em relação aos negros, tidos como culpados pela sua miserabilidade e desgraça, também é ressaltada por Ribeiro (2006). Ele aponta que esta nação "nunca fez nada pela massa negra que a construíra. Negou-lhe a posse de qualquer pedaço de terra para viver e cultivar, de escolas em que pudesse educar seus filhos, e de qualquer ordem de assistência. Só lhes deu, sobejamente, discriminação e repressão" (RIBEIRO, 2006, p. 204). O fim da escravidão alterou pouco a condição negra no Brasil: 
Os ex-escravos abandonam as fazendas em que labutavam, ganham as estradas à procura de terrenos em que pudessem acampar, para viverem livres como se estivessem nos quilombos, plantando milho e mandioca para comer. Caíram, então, em tal condição de miserabilidade que a população negra reduziu substancialmente [...] pela terrível miséria a que foram atirados (RIBEIRO, 2006, p. 203).

De acordo com o autor, a sociedade que daí resultou apresenta insanáveis incompatibilidades, das quais se destacam "[...] a incapacidade de assegurar um padrão de vida, mesmo modestamente satisfatório, para a maioria da população nacional; a inaptidão para criar uma cidadania livre e, em consequência, a inviabilidade de instituir-se uma vida democrática" (RIBEIRO, 2006, p. 201).

Segundo Furtado (2007), o Brasil se apresentava com certo atraso do ponto de vista de uma nação moderna, e isso se constata já no início do século XIX. Conforme o autor, qualquer que fosse a forma como se processasse a independência, era uma única classe que sempre ocupava o poder, expressa desde o início pelos grandes senhores agrícolas.

Nessa mesma direção, Ribeiro (2006, p. 20) acrescenta que diante desse contexto social não foi possível desenvolver uma democracia institucional, com base em governos locais e que "as instituições republicanas, adotadas formalmente no Brasil para justificar novas formas de exercício do poder pela classe dominante, tiveram sempre como seus agentes junto ao povo a própria camada proprietária”. Além disso, indica também como uma das causas do atraso do país a forma de ordenação da sociedade, em que a atenção não estava voltada ao povo brasileiro, aos seus direitos e às suas condições de existência, mas, sim, estava voltada ao atendimento da feitoria exportadora. Holanda (1995, p. 31) complementa:

A tentativa de implantação da cultura europeia em extenso território, dotado de contradições naturais, se não adversas, largamente estranhas à sua tradição milenar, é, nas origens da sociedade brasileira, o fato dominante e mais rico em consequências. Trazendo 
de países distantes nossas formas de convívio, nossas instituições, nossas ideias, e, timbrando em manter tudo isso em ambiente muitas vezes desfavorável e hostil, somos ainda hoje uns desterrados em nossa terra.

No Brasil, os processos de industrialização e urbanização, conforme destaca Ribeiro (2006), são processos complementares e que procederam a uma nova configuração ao Brasil, no início do século XX, marcado pelo êxodo rural e o espantoso crescimento da população urbana, num salto de 12,8 milhões, em 1940, para 80,5 milhões, em 1980. Para o autor:

[...] vivemos um dos mais violentos êxodos rurais, tanto mais grave porque nenhuma cidade brasileira estava em condições de receber esse contingente espantoso de população. Sua consequência foi a miserabilização da população urbana e uma pressão enorme na competição por empregos (RIBEIRO, 2006, p. 182).

Ocorre repentino inchaço das cidades, principalmente em São Paulo e Rio de Janeiro. Diante do grande impacto da industrialização na sociedade brasileira, o autor chama a atenção para a formação das classes sociais nas cidades, reproduzindo e fortalecendo o fosso entre ricos e pobres. E, ainda em relação às classes sociais, complementa:

As classes sociais brasileiras não podem ser representadas por um triângulo, com um nível superior, um núcleo e uma base. Elas configuram com um losango, com um ápice finíssimo, de pouquíssimas pessoas, e um pescoço, que se vai alargando daqueles que se integram no sistema econômico como trabalhadores regulares e como consumidores. Tudo isso como um funil invertido, em que está a maior parte da população, marginalizada da economia e da sociedade, que não consegue empregos regulares nem ganhar o salário mínimo (RIBEIRO, 2006, p. 195).

Diante dessa situação, Ribeiro (2006) faz uma crítica aos governos que só buscam a saída para o desenvolvimento do país por meio da venda de 
indústrias criadas no passado e a inserção no mercado global. E questiona: “[...] até quando este país continuará sem seu projeto de desenvolvimento autônomo e autossustentável?” (p. 187). Acrescenta ainda:

Não há, nunca houve aqui um povo livre, regendo seu destino na busca de sua própria prosperidade. O que houve e o que há é uma massa de trabalhadores explorada, humilhada e ofendida por uma minoria dominante, espantosamente eficaz na formulação e manutenção de seu próprio projeto de prosperidade, sempre pronta a esmagar qualquer ameaça de reforma da ordem social vigente (RIBEIRO, 2006, p. 408).

O autor observa que o Governo de Getúlio Vargas, na década de 1950, volta-se para uma política de capitalismo com foco no Estado, e que passou a ser substituída por um processo de industrialização substitutiva, no início da década de 1960, com o governo de Juscelino Kubitschek. O resultado disso era para ser uma Revolução Industrial, porém Ribeiro (2006) destaca que, por um lado, os resultados foram exitosos, diante de uma modernização dessas indústrias substitutivas, o que dinamizou a economia nacional, mas, por outro lado, houve uma concentração elevada em São Paulo, fazendo deste um polo de colonização interna, com um crescimento acelerado. Isso provocou uma diminuição no desenvolvimento dos demais estados. A partir desse processo, “[...] as metrópoles do Brasil absorveram imensas parcelas da população rural que, não tendo lugar no seu sistema de produção, se avolumaram como massa desempregada, gerando uma crise sem paralelo de violência urbana" (RIBEIRO, 2006, p. 186).

Ianni (2004) avalia que, ao longo do século XX, ocorre uma transição econômica de economia primária exportadora para uma industrialização substitutiva de importações. E, nesse percurso, o Estado se torna um lugar privilegiado para o capital, pois intensifica, em vários momentos, a sua atuação nas forças produtivas, na economia brasileira. O poder do Estado se fortalece cada vez mais em termos econômicos e políticos, 
principalmente a partir da década de 1960, quando se desenvolveu um complexo industrial-militar.

O Estado, aos poucos, principalmente a partir do golpe de Estado, alarga sua presença na economia brasileira, momento em que "[...] desenvolveu-se uma aliança entre as Forças Armadas, e não apenas o Exército, com a indústria, a burguesia industrial" (IANNI, 2004, p. 253). Nesse período, a questão social é transformada, na maior parte das vezes, num problema de polícia. As lutas, os movimentos sociais, as greves sempre são capitalizadas pelos interesses representados pelo governo.

Ainda, para Ianni (2004), a industrialização no Brasil ocorreu de forma tardia e, ao longo da história do capitalismo no Brasil, houve a oscilação em duas tendências principais: em alguns momentos inclinava-se para um capitalismo nacional, autônomo, com o apoio do mercado interno e, em outros momentos, predominava um capitalismo associado, com articulação ao internacional, buscando o benefício das multinacionais. Embora com muitos problemas, disputas, o que passou a predominar foi o capitalismo associado, ou seja, um sistema econômico associado com as multinacionais, tendo como matriz os Estados Unidos, países da Europa e o Japão. Essa forma de capitalismo não é única, mas é a que mais se expande, desde a década de 1950. O autor destaca as desigualdades que resultaram desse processo:

Sob vários aspectos, a formação do capitalismo no Brasil realiza-se de modo desigual e combinado. Desigual e combinado em termos não só econômicos, mas também sociais, políticos e culturais. As diversidades regionais, raciais e culturais escondem sérias desigualdades sociais, econômicas e políticas. Mas o capitalismo floresce, beneficiando-se e aproveitando as desigualdades que se escondem nas diversidades (IANNI, 2004, p. 261).

Dessa forma, reduz-se significativamente a possibilidade de um projeto de capitalismo nacional, soberano e autossustentado, pois, de acordo 
com Ianni (2004, p. 255), "o capitalismo associado, no qual predominam a empresa e o banco estrangeiros radicados nos países dominantes, parece ser o coroamento desse largo processo".

Em 1982, mediante as contradições sociais que se desencadeavam ao desenvolvimento nacional, o crescimento explosivo da urbanização entra em crise e anuncia a sua impossibilidade de continuar crescendo dessa forma, pois, como explicita Ribeiro (2006, p. 184):

\footnotetext{
Primeiro, a estrutura agrária dominada pelo latifúndio que, incapaz de elevar a produção agrícola ao nível do crescimento da população, de ocupar e pagar as massas rurais, as expulsa em enormes contingentes do campo para as cidades, condenando a imensa maioria da população à marginalidade. Segundo, a espoliação estrangeira, que amparada pela política governamental fortalecera seu domínio, fazendo-se sócia da expansão industrial, jugulando a economia do país pela sucção de todas as riquezas produtivas.
}

O autor, ao analisar o impacto da industrialização no país, menciona que uma das transformações importantes foi a passagem de um sistema tecnológico, com alta exigência de mão-de-obra para um sistema que utilizava uma tecnologia mecanizada, que, mediada por motores, viu-se cada vez menos dependente da força de trabalho disponível, tendendo, portanto, à marginalização. Ocorre uma inversão de um país que antes precisava importar mão-de-obra para uma situação em que essa mão-de-obra foi se tornando excedente, conforme destaca Ribeiro (2006, p. 238): “é o trabalhador brasileiro que se torna obsoleto como uma força descartável dentro da economia nacional".

Uma transformação mais recente, ainda mais radical, é a revolução tecnológica, pois "se uma vez mais nos deixarmos fazer consumidores de seus frutos, em lugar de dominadores de sua tecnologia nova, as ameaças sobre a nossa sobrevivência e sobre a soberania nacional serão ainda mais intensas" (RIBEIRO, 2006, p. 239). 
Por fim, cumpre salientar que as transformações seculares ocorridas na formação da sociedade brasileira, desde o período colonial, apresentam na sua essência a estrutura de uma sociedade capitalista desigual, que tornou o Brasil um país rico, mas com os maiores índices de concentração de renda e de desigualdades sociais do mundo.

\section{ELITISMO NA EDUCAÇÃO SUPERIOR}

Tradicionalmente o sistema educacional brasileiro nos diferentes níveis de ensino é considerado excludente, pois reflete as desigualdades sociais, econômicas, culturais e políticas do país. Conforme destaca Saviani (2011), tanto no tipo de sociedade antiga ou escravista, quanto no tipo de sociedade medieval ou feudal, a escola foi como uma modalidade educacional secundária, complementar, e isso se dava "porque a modalidade principal de educação continuava sendo o trabalho, uma vez que a grande massa, a maioria, não se educava através da escola, mas através da vida, ou seja, do processo de trabalho" (p. 82).

Saviani (2013) descreve que a primeira política educacional no Brasil foi a "educação pública religiosa”, uma vez que contava com subsídios da Coroa Portuguesa. Sua origem se deu com a chegada dos jesuítas ao Brasil, em 1549, e essa modalidade, coordenada pelo Padre Manoel da Nóbrega, destinava-se aos filhos de índios e de colonos portugueses. Em seguida, foi suplantada por um plano geral dos jesuítas, que privilegiou a centralidade nas "humanidades" e a formação das elites. O ensino jesuíta no Brasil foi até a metade do século XVIII, quando, em 1759, os jesuítas foram expulsos pelo primeiro-ministro do rei de Portugal, o Marquês de Pombal.

Assim, conforme descreve Teixeira (1989, p. 61), a educação no projeto colonial era destinada primordialmente à elite branca:

Os índios quando não eram escravizados, recebiam uma educação de evangelização nos seus próprios aldeamentos, sob a guarda e a proteção dos jesuítas. Os escravos eram educados pelo trabalho 
forçado e vida nas senzalas. O branco recebia uma educação de qualidade, baseada no saber medieval greco-latino, em sua interpretação teológica ou aristotélico-tomista.

A partir do século XVIII, as reformas pombalinas se inserem no âmbito das reformas modernizadoras inspiradas pelo Iluminismo, que se contrapõem ao ensino religioso. As escolas jesuítas foram fechadas no Brasil e substituídas por "aulas régias", mantidas pela Coroa, porém não foram desenvolvidas totalmente por falta de recursos, conforme nos aponta Saviani (2013). O autor afirma que a partir da independência política do Brasil, em 1822, retoma-se o debate relacionado ao problema da instrução pública nacional. Várias propostas foram apresentadas, com a ideia até de um sistema nacional de ensino, mas que não chegaram a se efetivar. A Proclamação da República significou, portanto, “[...] uma vitória das ideias laicas. Decretou-se a separação entre a Igreja e o Estado e a abolição do ensino religioso nas escolas" (SAVIANI, 2013, p. 125).

Com relação ao ensino superior, Oliven (2005) aponta que no Brasil não havia ensino superior até o século XIX. Os estudantes da elite colonial para obter a graduação precisavam se deslocar até a metrópole. Assim, os filhos das classes dominantes, que estudavam em escolas reais, já eram preparados para frequentar a Universidade de Coimbra, em Portugal.

Teixeira (1989) complementa essa reflexão, enfatizando que a Universidade de Coimbra foi a primeira universidade do Brasil, e que nos primeiros três séculos do Brasil-colônia, graduaram-se, nessa universidade, 2.500 jovens nascidos no Brasil. O autor aponta para as dificuldades que o Brasil tinha para consolidar uma universidade brasileira, daí que se originavam as escolas profissionalizantes, uma marca da educação superior, como já mencionado. Sobre a educação no período colonial, assim descreve o autor:

A sociedade que implantava na colônia era, assim, uma sociedade arcaica, de cultura oral, anterior à palavra impressa, fundada na 
escravidão, no patriarcalismo rural e na burocracia colonial, explorada pelo monopólio mercantilista da metrópole, como uma superestrutura religiosa de culto dos santos [...], tudo dominado por um quadro clerical de padres letrados, pregadores e educadores, que lembrariam um corpo de intelectuais (TEIXEIRA, 1989, p. 57).

Com a chegada da família real no Brasil, em 1808, começaram a ser implementadas por Dom João VI as primeiras faculdades, consideradas profissionalizantes e seculares. Como aponta Teixeira (1989, p. 67), são criadas a "[...] Escola de Cirurgia, Academias Militares, Escola de Belas Artes, Museu e Biblioteca Nacional e Jardim Botânico, mas não se fala em Universidade”. Essa dificuldade de se implantar universidades no Brasil era substituída ou compensada por um ensino profissionalizante, caracterizado por um saber útil e aplicado.

Ribeiro (2006) contextualiza que, ao consolidar-se o Estado monárquico, se tornaram necessárias a criação de novas escolas médias e superiores para formar novas gerações de letrados,

\begin{abstract}
[...] para a magistratura e para o Parlamento, de bacharéis nativos, de engenheiros militares para a defesa, e de médicos para cuidar da saúde dos ricos. A cultura vulgar e, com ela, a maioria das técnicas produtivas, entregues a seus produtores imediatos, só muito lentamente começariam a modernizar-se. Como à criação das escolas para as elites não correspondeu qualquer programa de educação de massas, o povo brasileiro permaneceu analfabeto (RIBEIRO, 2006, p. 231).
\end{abstract}

Com base na análise de Teixeira (1989), o século XIX, mesmo após a Independência do Brasil, continuou sendo um prolongamento do período colonial, tendo o país mergulhado numa profunda estagnação econômica, política e social. Para o autor, "o desenvolvimento da educação e do ensino superior no Império constituem exemplos de quanto uma elite, identificada com a Metrópole colonizadora e habituada à submissão a ela no seu sistema de valores, pode revelar-se incapaz de elevar-se à altura do projeto 
nacional" (TEIXEIRA, 1989, p. 71). Dessa forma, durante o longo período do Império no Brasil, até o início do século XX, o Brasil não dispunha de outras formas de escolas, senão as profissionais, voltadas principalmente para os cursos superiores de Engenharia, Medicina e Direito.

De acordo com Saviani (2011), no final do século XIX, quando muitos dos países organizaram seus sistemas de ensino, o Brasil permaneceu atrasado, tardio, em termos de educação para a maioria da população, criando um déficit histórico. Chegou a ser considerado como um dos países com os maiores índices de analfabetismo, com um percentual de 85\% de analfabetos em relação à população em geral.

A partir do momento em que o país inicia seu desenvolvimento, com o acelerado processo de urbanização e industrialização, “[...] as pressões sociais em torno da instrução pública intensificaram-se, difundindo-se o entendimento do analfabetismo como uma doença, uma vergonha nacional, que devia ser erradicada" (SAVIANI, 2013, p. 126).

No período da Primeira República (1889-1930), Oliveira (2013) aponta que no Brasil a ideia da universalização e democratização do ensino estava direcionada principalmente para os primeiros anos de ensino e mesmo assim não se efetivava em nenhum dos graus de ensino. Esse caminho da democratização começa a se efetivar quando o Estado toma a educação como um mecanismo para a preparação da mão-de-obra da indústria que estava nascente.

Na década de 1920, como sinaliza Romanelli (2012), surge a primeira organização de ensino superior, a universidade. É criada por meio de uma determinação do Governo Federal a Universidade do Rio de Janeiro, agregando três escolas superiores já existentes, nas áreas de Medicina, Direito e Escola Politécnica. Assim também foram se sucedendo em outros estados com a criação de novas universidades.

Portanto, é na Modernidade, no modo de produção capitalista, que o conhecimento sistemático, as expressões letradas e escritas passam a ser valorizadas, tendo em vista principalmente as condições de vida na 
cidade, haja vista que há um deslocamento do eixo produtivo da agricultura, do meio rural para a indústria, do meio urbano. A década de 1930 passa a ser um forte marco para as preocupações em termos de legislação da educação em nível nacional (SAVIANI, 2011).

Em 1931, por meio da Reforma Francisco Campos, foi decretado o Estatuto das Universidades com vigência até 1961, que passou a adotar o regime universitário para o ensino superior. Conforme os parâmetros deste estatuto, a primeira universidade criada foi a Universidade de São Paulo (USP), em 1934, que rompeu com o modelo tradicional, inovando seus objetivos. A partir daí começaram a surgir várias universidades públicas e privadas que foram se espalhando pelo país, somando-se 46 no ano de 1969 (ROMANELLI, 2012).

Ainda, conforme destaca Romanelli (2012), os objetivos do referido Estatuto eram vastos, mas continham uma visão distorcida, tanto da realidade brasileira, quanto dos limites que qualquer instituição escolar comporta. Nas palavras da autora, os objetivos da universidade moderna têm sido "a investigação científica e o preparo para o exercício profissional. [...] Mas, apesar de ambos constarem da declaração de princípios da legislação, a universidade brasileira vem perseguindo, desde a sua criação, apenas os objetivos ligados à formação profissional" (2012, p. 135).

$\mathrm{O}$ acesso à universidade, com o estatuto, continua sendo o vestibular, uma prática que se perpetua até os dias atuais, tendo algumas modificações, porém apenas no que se refere à nomenclatura e quanto ao tipo de provas, pois o seu caráter excludente e meritocrático ainda permanece.

A Reforma Francisco Campos também propôs a reforma no ensino secundário e, conforme menciona Romanelli (2012), iniciam-se os indícios de um ensino "elitista", tendo em vista a proposição de um ensino secundário com vastos conteúdos, subdivididos em dois ciclos: fundamental, de cinco anos, e um básico, de dois anos, sendo o primeiro considerado uma condição obrigatória para o ingresso em qualquer escola de ensino superior e o segundo, em escolas determinadas. Esse currículo era conhecido 
como enciclopédico. O caráter "elitista" do ensino secundário também se somava a um sistema de avaliação rígido, controlado por um exagerado número de provas e exames, tornando o sistema altamente seletivo. $\mathrm{Na}$ visão da autora:

[...] para um contexto social que começava a despertar para os problemas do desenvolvimento e da educação, numa sociedade cuja maioria vivia na zona rural e era analfabeta e numa época em que a população da zona urbana ainda não estava totalmente atingida, nem sequer pela educação primária, pode-se imaginar a camada social para qual havia sido elaborado um currículo assim tão vasto (ROMANELLI, 2012, p. 138).

Nesse sentido, a reforma de Francisco Campos não teve muita contribuição para o avanço do ensino naquele contexto. Além disso, vai se desmembrando uma estrutura educacional dualista, subdividida, de um lado, por uma educação primária e profissional para os pobres e, de outro lado, o ensino secundário e superior para os ricos (ROMANELLI, 2012).

Sobre o aspecto dualista, delegado ao ensino secundário, Oliveira (2013, p. 275) enfatiza que "o caminho escolar das elites era: do primário ao ginásio, do ginásio ao colegial e, posteriormente, a opção por qualquer curso superior; o caminho das camadas populares, caso escapassem da evasão, ia do primário aos cursos profissionalizantes”.

Em seguida, o movimento de renovação do sistema educacional, a partir do Manifesto dos Pioneiros da Educação Nova, faz a crítica a essa estrutura educacional e propõe algumas mudanças na educação reconhecendo-a como um direito individual e um dever do Estado. Problematiza a estrutura de privilégio da escola a alguns, propondo que a educação deveria ser assegurada de forma pública gratuita e obrigatória, o que Romanelli (2012) considerou como uma visão avançada para a época por parte dos educadores. 
Santos (2011, p. 29) enfatiza que as lutas pela democratização, em contraposição ao caráter elitista que marca a educação brasileira, se fizeram presentes desde a sua gênese e que "em diversos momentos da história da educação, as lutas pela expansão do sistema e ruptura com os privilégios são uma constante". Com isso, pode-se constatar que as reformas educacionais, as legislações educacionais geralmente tendem a estar a favor de uma ala dominante da sociedade, reproduzindo as contradições existentes e as desigualdades sociais do sistema capitalista.

A expansão da educação foi marcada nos diversos momentos de sua história por concepções que, como explicita Romanelli (2012), representam o predomínio de velhas concepções, enquanto o Manifesto representava uma concepção jovem e inovadora da educação.

Saviani (2013) destaca que, a partir da década de 1930, aconteceram várias medidas relativas à educação, como as reformas do ministro Francisco Campos, o Manifesto dos Pioneiros da Educação Nova e a Constituição de 1934, que exigia a elaboração de um plano nacional de educação e a fixação de diretrizes da educação nacional. Mas ressalta que foi somente a Constituição de 1946 que definiu a educação:

[...] como um direito de todos e o ensino primário como obrigatório para todos e gratuito nas escolas públicas, e ao determinar à União a tarefa de fixar as diretrizes e bases da educação nacional, abria a possibilidade da organização e instalação de um sistema nacional de educação como instrumento de democratização da educação pela via da universalização da educação básica (SAVIANI, 2013, p. 127).

É importante frisar que na década de 1930, a partir da Reforma Francisco Campos, que regulamentava toda a educação superior pública e privada, houve uma disputa pelo controle da educação entre elites laicas e católicas. Conforme descreve Pegoraro (2013), a Igreja, sentindo-se impossibilitada para controlar a educação pública, buscou criar suas próprias universidades, a partir da década de 1940. Na visão do autor, essa atitude 
não rompeu totalmente com o Estado, pois a educação superior católica sempre esteve paralela ao setor público e mantinha uma dependência financeira do Estado.

No período entre 1945 a 1965 há uma integração da educação superior, sendo criadas várias universidades federais, principalmente originadas da junção de institutos federais, estaduais e particulares, além da federalização de muitas instituições. Até o início de 1960, ocorreu um relativo crescimento da educação superior, pois esse ensino passa a ser uma exigência cada vez maior para o mercado de trabalho, principalmente nas empresas e burocracias estatais, conforme aponta Pegoraro (2013). O autor, mencionando os dados apresentados por Oliven (1990, apud PEGORARO, 2013, p. 65), demonstra que "o crescimento médio anual das matrículas na educação superior passou de 2,4\%, no período de 1932 a 1945, para 12,5\%, no período de 1945 a 1964”.

Esse período, considerado como "populista", apresentou-se como um momento importante para o debate sobre a democratização do acesso à educação superior, pois, conforme destaca Oliveira (2013, p. 279), foi “[...] marcado pela perspectiva da crença no Estado intervencionista e promotor de políticas de bem-estar social. É também o período da chamada democracia desenvolvimentista via crescimento econômico do Estado". O autor considera que houve uma "massificação" do ensino superior, e chegou-se até a discutir sobre a supressão do vestibular e a universalização dessa modalidade de ensino. Houve um investimento maior na educação superior que nas séries iniciais.

A Lei de Diretrizes e Bases da Educação (LDB), que tramitou por treze anos no Congresso e foi aprovada em 1961, não mencionava que a educação superior deveria ser ofertada principalmente por universidades. A partir de então, três órgãos se responsabilizavam pela criação de novos cursos: os Conselhos Estaduais, o Conselho Federal de Educação e as universidades. Nesse período, o setor que mais se desenvolveu foi o privado (PEGORARO, 2013). 
Para a educação básica, a Lei também não correspondeu àquela expectativa prevista pela Constituição de 1946, pois o texto previa a isenção de responsabilidades no cumprimento quanto à obrigatoriedade escolar, limitando-se ao "[...] comprovado estado de pobreza do pai ou responsável e a insuficiência de escolas" (SAVIANI, 2013, p. 127).

Em 1964, a partir do golpe civil e militar, os militares passaram a ter uma ingerência direta nas universidades. Em 1968, intensificaram-se no Brasil e em vários países as mobilizações pela recusa do autoritarismo por parte dos militares, que vinha se manifestando inclusive na educação. Nesse mesmo ano é aprovada a Reforma Universitária, a Lei no 5.540, de 1968, que implementou várias mudanças na educação superior, principalmente na área pública. Entre as principais medidas, destacou-se a abolição da cátedra, substituída por departamentos como unidades de ensino e pesquisa, a criação de institutos básicos e o vestibular passou a ser classificatório. A partir dessas reformas houve um crescimento de instituições privadas, de pequeno porte, e muitas delas tiveram sua origem a partir das escolas secundárias. Essa reforma, na medida em que desobriga a oferta de ensino superior no âmbito público, incentiva a oferta pela lógica privatizante do mercado (PEGORARO, 2013).

Nesse período, a expansão do ensino superior se deu, primordialmente, sob a égide do mercado, e o Estado foi se distanciando da oferta de vagas públicas. Além disso, destaca-se que os cursos eram predominantemente de cunho profissionalizante, voltados para a formação da elite dirigente.

O período que vai de 1964 a 1984 é a fase conhecida como "democracia doada”, pois conforme destaca Oliveira (2013, p. 284), "a democratização para os militares e liberais conservadores e autoritários é fruto de doações do poder público, como, por exemplo, a ampliação de vagas do ensino superior”. Nesse período, a educação passou por um processo de forte desmobilização política, delineada por medidas e reformas que se adaptavam ao modelo econômico vigente, com uma visão tecnicista e empresarial da educação. 
A partir da Reforma Universitária, conforme destaca Oliven (2005), passaram a ser criados cursos com pequena duração e em áreas técnicas. Também, com o fim da cátedra vitalícia, os professores ganharam uma notoriedade em sua profissão, por meio de suas carreiras com dedicação exclusiva, regime de tempo integral e a indissociabilidade entre o ensino, a pesquisa e a extensão, criando condições para o desenvolvimento da pós-graduação no país.

Saviani (2013, p. 127) aponta a limitação e o caráter dualista da política educacional, principalmente com a Lei no 5.692/1971, que "fixa as diretrizes e bases para o ensino de primeiro e segundo graus", pois previa a profissionalização universal e compulsória do segundo grau. Nas palavras do autor, o Grupo de Trabalho que propôs o texto estava “[...] sugerindo que as elites reservavam para si o ensino preparatório para ingresso no nível superior, relegando a população ao ensino profissional, destinado ao exercício das funções subalternas" (2013, p. 127). O autor menciona que a lei faz a distinção entre:

[...] terminalidade ideal ou legal, correspondente à escolaridade completa de primeiro e segundo graus com a duração de 11 anos, e terminalidade real, preconizando-se a antecipação da formação profissional para garantir que todos, mesmo aqueles que não chegassem ao segundo grau ou não completassem o primeiro grau, saíssem da escola com algum preparo profissional para ingressar no mercado de trabalho (SAVIANI, 2013, p. 128).

Portanto, essa era mais uma medida dualista que manifestava um tratamento desigual na política educacional e uma forma de distanciar a chegada ao ensino superior, principalmente às camadas mais pobres. Saviani (2013) faz uma crítica a esse dualismo, uma vez que ele ainda se faz presente nos dias de hoje na política educacional, não apenas no ensino médio ao separá-lo do técnico, mas também "quando se advoga, no ensino superior, em favor dos centros de excelência destinados a ministrar 
às elites um ensino de qualidade articulado com a pesquisa em contraste com instituições que ofereceriam ensino sem pesquisa" (2013, p. 128).

Em relação à fase militar no Brasil, Germano (2000) enfatiza a escalada repressiva que foi desencadeada nesse período de ditadura e que influenciou diretamente na educação brasileira. Na educação superior houve várias ocupações nas universidades, afastamento de professores, ocupação de reitorias por militares e, principalmente, um incentivo à privatização, ficando de lado a educação pública. Esse período deixou profundas marcas para a sociedade como um todo, pois houve um grande crescimento econômico, a abertura para o capital externo e, paralelamente, um aumento abrupto das desigualdades sociais entre ricos e pobres. Em resumo, o autor sintetiza que a política dos militares se caracterizou como uma expressão de dominação burguesa e a política educacional, inserida nesse contexto, resultou dessas correlações de forças.

O ensino superior, conforme descreve Oliveira (2013), passou por um crescente processo de privatização, controle e deteriorização. $\mathrm{O}$ autor ainda complementa:

A "democratização doada", via expansão das matrículas do ensino superior, despreza o contexto socioeconômico e a situação educacional do país, tornando-se na realidade, uma pseudodemocratização, na medida em que procura 'universalizar', ou seja, tornar acessível às massas um ensino qualquer (OLIVEIRA, 2013, p. 286).

Na década de 1970, Saviani (2010) destaca a crise na sociedade capitalista, que conduziu a reestruturação de novos processos produtivos por meio da substituição do modelo fordista para o modelo toyotista, o que também influenciou diretamente no campo educacional. Nesse modelo do toyotismo, exigem-se trabalhadores cada vez mais flexíveis, polivalentes e em lugar de estabilidade no emprego há uma disputa cada vez mais por aumentar a produtividade. Na educação, a crença era da sua contribuição para esse novo processo econômico-produtivo. 
Conforme Oliveira (2013), o final da década de 1970 e a década de 1980 é a fase da "democratização relativa”, um período marcado por intensas mobilizações populares e a luta por eleições diretas, no qual foi consagrada a "transição democrática" para a democracia política brasileira e ocorreu a eleição direta para presidente da República. O autor descreve como um momento importante para a vida universitária, pois “[...] a universidade começa a intensificar uma posição mais crítica perante os problemas da sociedade, bem como a assumir sua parcela de responsabilidade na construção de um país realmente democrático" (2013, p. 293).

Com relação ao acesso à educação superior, na década de 1980, as produções teóricas passaram a denunciar cada vez mais o caráter seletivo e discriminatório do vestibular, e as pressões são intensas no sentido de exigir mudanças do governo. Nesse período, o Ministério da Educação promove vários debates sobre o vestibular, e as universidades buscam autonomia para propor seus próprios modelos de seleção (OLIVEIRA, 2013).

Ao retratar as desigualdades educacionais como uma herança histórica no Brasil, Pinto (2004) situa que a educação superior se expandiu principalmente pela via da privatização, no período entre 1980 a 2002. Em relação ao acesso à educação superior, naquele período, o autor destaca a "[...] alegada injustiça do sistema atual, uma vez que, argui-se, os alunos vindos de famílias de maior poder aquisitivo frequentariam as Instituições de Ensino Superior (IES) públicas ao passo que os alunos mais pobres iriam para as IES privadas" (PINTO, 2004, p. 16). Pode-se dizer que havia nesse período dois movimentos: um de inclusão, por meio da oferta do ensino privado, e outro de exclusão, por meio do caráter meritocrático do vestibular. 


\section{CONSTITUIÇÃO FEDERAL DE 1988: PERSPECTIVAS DE DEMOCRATIZAÇÃO}

A partir da década de 1980, a sociedade brasileira vive um processo intenso de participação popular e mobilização em prol de uma nova constituinte, que significou um grande marco em termos de democratização. A Assembleia Nacional Constituinte de 1987-88 ocorreu durante o primeiro governo civil e, no entendimento de Farenzena e Luce (2013, p. 268),

[...] foi premida pelas sombrias transações para o restabelecimento do regime democrático [...] e pelas demandas dos mais variados grupos sociais, os quais, na falta de bases democrático-representativas mais consolidadas para mediar as relações Estado-sociedade, buscaram intervir diretamente na elaboração do texto constitucional.

Trata-se de um momento significativo, em que a educação é reconhecida, perante a lei, como um dever do Estado e da família e um direito de todos (BRASIL, 1988). Cury (2002) reconhece a legislação como um instrumento importante para a garantia dos direitos sociais. Também salienta o avanço da educação ancorado numa concepção democrática de sociedade, em que o Estado é invocado a prover esse bem, tanto na garantia de igualdades quanto na redução das desigualdades, advindas dos conflitos relativos à distribuição da riqueza capitalista. Dessa forma, o autor ressalta que esta relação entre direito e dever implica a possibilidade de acionar instrumentos jurídicos capazes de viabilizar e fazer valer esse direito na falta do atendimento à educação escolar.

O Estado federativo foi recuperando suas bases, tendo como características as eleições diretas, a descentralização fiscal da Constituição Federal de 1988, enfim, a autoridade política em cada nível de governo passou a ser soberana e independente das demais. Sallum Júnior (2003), ao analisar algumas das mudanças políticas ocorridas no Estado brasileiro nas últimas duas décadas do século XX, focaliza dois processos que alteraram o 
Estado, nas suas relações econômica e social: a democratização política e a liberalização econômica.

Sobre o processo de democratização política, o autor considera que houve um notável progresso brasileiro no sentido do aprofundamento da democracia, porém essa democratização não deixou de ser alvo dos ataques da elite empresarial. Sobre a liberalização econômica, destaca a acolhida ao capital estrangeiro e a privatização das empresas estatais, que se iniciaram ainda na década de 1980. O Estado passou a adotar um programa liberal de governo, com ênfase especialmente nos governos de Fernando Henrique Cardoso. Assim, ao se referir às últimas décadas do século XX, Sallum Júnior (2003, p. 50) resume:

[...] por maiores que tenham sido as mudanças ocorridas, o Brasil
não escapou de sua condição periférica. A retomada do crescimen-
to acelerado e a consolidação do Mercosul não serão suficientes
para permitir que isso ocorra. Superar essa condição exige a inclu-
são social e econômica dos mais pobres, que ainda permanecem
à margem das conquistas materiais da civilização moderna. Este é
o desafio mais difícil e mais necessário para a sociedade brasileira
superar neste século XXI.

No contexto neoliberal, a partir da década de 1990, o sentido que veio a ter a teoria do capital humano é a lógica de um status de empregabilidade, da competitividade, e a educação passa a ser um meio para acessar a esse fim e não um fim coletivo, mas um meio individual de cada um buscar as competências necessárias para sua inserção e na via de competir no mercado de trabalho. Nessa lógica "[...] a educação passa a ser entendida como um investimento em capital humano individual que habilita as pessoas para a competição pelos empregos disponíveis" (SAVIANI, 2010, p. 430).

Além disso, a educação foi sendo atrelada cada vez mais pela iniciativa privada e o Estado tornou-se cada vez mais reduzido de suas possibilidades para iniciativas do setor público. Na educação superior, Saviani (2010) ressalta que desde o governo de Fernando Henrique Cardoso a 
política educacional vem seguindo variados modelos, buscando atender essa nova concepção de educação para o mercado. Nas palavras do autor, essa diversificação de modelos também "respalda a abertura indiscriminada de faculdades e cursos guiados fundamentalmente pelos assim chamados interesses de mercado, no espírito das 'universidades corporativas' que se vêm multiplicando nos Estados Unidos por iniciativa de grandes empresas" (2010, p. 441).

A Constituição de 1988 garantiu a autonomia universitária, e as universidades, a partir da década de 1990, com o Decreto nº 99.490, passaram a realizar seus próprios vestibulares, ocorrendo uma diversificação maior nos processos seletivos, mantendo, porém, o caráter elitista e meritocrático (OLIVEIRA, 2013).

Sallum Júnior (2003, p. 49) aponta que no período em que Lula assume o poder, o governo caracteriza-se por um projeto liberal-desenvolvimentista, dando continuidade à hegemonia liberal estabelecida, "porém seu objetivo não é reconstruir o Estado empresarial, mas reformar o Estado para que possa estimular o desenvolvimento privado e a igualdade social".

Nas últimas décadas, e mais especificamente nos governos de Lula e de Dilma, tornou-se necessário o debate para a implantação de políticas sociais mais efetivas, tendo em vista um cenário marcado por profundas desigualdades sociais e educacionais. É nesse cenário que as ações afirmativas de acesso ao ensino superior emergem no sentido de abranger grupos historicamente marginalizados.

As ações afirmativas situam-se, portanto, num contexto histórico de elitização do ensino superior em que o acesso precisa ser ampliado. Nessa análise, Santos e Cerqueira (2009) destacam as perversas consequências para o ensino superior tendo em vista as escolhas econômicas neoliberais do país desde a década de 1990. Os autores arriscam dizer que, diante desse sistema tradicionalmente elitista de ensino, o governo de Lula "tem demonstrado, ainda que contraditoriamente, um interesse e uma disposição em favorecer o acesso e a permanência de determinados setores da 
sociedade até então excluídos deste nível de escolarização" (SANTOS; CERQUEIRA, 2009, p. 14).

A partir desse percurso histórico sobre a educação brasileira, constatou-se que as desigualdades sociais e a elitização do acesso à educação superior apresentam a sua marca de origem - de um país que investiu tardiamente na educação - e a influência do caráter profissionalizante e da lógica do privado no seu percurso. 